\title{
Kinetics of silicide formation over a wide range of heating rates spanning six orders of magnitude
}

Manel Molina-Ruiz, Aitor F. Lopeandía, Marta Gonzalez-Silveira, Gemma Garcia, Inma Peral, Maria T.

Clavaguera-Mora, and Javier Rodríguez-Viejo

Citation: Appl. Phys. Lett. 105, 013113 (2014);

View online: https://doi.org/10.1063/1.4890106

View Table of Contents: http://aip.scitation.org/toc/apl/105/1

Published by the American Institute of Physics

\section{Articles you may be interested in}

Formation of $\mathrm{Pd}_{2} \mathrm{Si}$ on single-crystalline $\mathrm{Si}(100)$ at ultrafast heating rates: An in-situ analysis by nanocalorimetry Applied Physics Letters 102, 143111 (2013); 10.1063/1.4800934

A scanning AC calorimetry technique for the analysis of nano-scale quantities of materials

Review of Scientific Instruments 83, 114901 (2012); 10.1063/1.4763571

In situ transmission electron microscopy investigation of the interfacial reaction between $\mathrm{Ni}$ and $\mathrm{Al}$ during rapid heating in a nanocalorimeter

APL Materials 2, 116102 (2014); 10.1063/1.4900818

Scanning AC nanocalorimetry study of $\mathrm{Zr} / \mathrm{B}$ reactive multilayers

Journal of Applied Physics 114, 214902 (2013); 10.1063/1.4833572

Studying exothermic reactions in the $\mathrm{Ni}$-Al system at rapid heating rates using a nanocalorimeter Journal of Applied Physics 113, 143509 (2013); 10.1063/1.4799628

Kinetics of solid-gas reactions characterized by scanning AC nano-calorimetry with application to Zr oxidation Applied Physics Letters 105, 171901 (2014); 10.1063/1.4900779

\section{Scilight}

Sharp, quick summaries illuminating the latest physics research

\section{Sign up for FREE!}

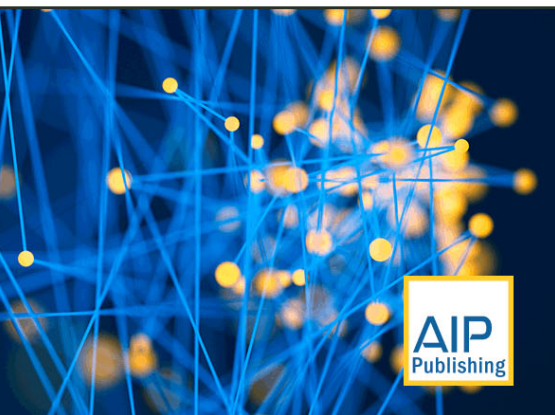




\title{
Kinetics of silicide formation over a wide range of heating rates spanning six orders of magnitude
}

\author{
Manel Molina-Ruiz, ${ }^{1}$ Aitor F. Lopeandía, ${ }^{1}$ Marta Gonzalez-Silveira, ${ }^{1}$ Gemma Garcia, ${ }^{1}$ \\ Inma Peral, ${ }^{2}$ Maria T. Clavaguera-Mora, ${ }^{1}$ and Javier Rodríguez-Viejo ${ }^{1,3, a)}$ \\ ${ }^{1}$ Grup de Nanomaterials i Microsistemes, Departament de Física, Universitat Autònoma de Barcelona, \\ 08193 Bellaterra, Spain \\ ${ }^{2}$ ALBA Synchrotron Light Facility, 08290 Cerdanyola del Vallès, Spain \\ ${ }^{3}$ MATGAS Research Centre, UAB Campus, 08193 Bellaterra, Spain
}

(Received 16 April 2014; accepted 27 June 2014; published online 10 July 2014)

\begin{abstract}
Kinetic processes involving intermediate phase formation are often assumed to follow an Arrhenius temperature dependence. This behavior is usually inferred from limited data over narrow temperature intervals, where the exponential dependence is generally fully satisfied. However, direct evidence over wide temperature intervals is experimentally challenging and data are scarce. Here, we report a study of silicide formation between a $12 \mathrm{~nm}$ film of palladium and $15 \mathrm{~nm}$ of amorphous silicon in a wide range of heating rates, spanning six orders of magnitude, from 0.1 to $10^{5} \mathrm{~K} / \mathrm{s}$, or equivalently more than $300 \mathrm{~K}$ of variation in reaction temperature. The calorimetric traces exhibit several distinct exothermic events related to interdiffusion, nucleation of $\mathrm{Pd}_{2} \mathrm{Si}$, crystallization of amorphous silicon, and vertical growth of $\mathrm{Pd}_{2} \mathrm{Si}$. Interestingly, the thickness of the initial nucleation layer depends on the heating rate revealing enhanced mass diffusion at the fastest heating rates during the initial stages of the reaction. In spite of this, the formation of the silicide strictly follows an Arrhenius temperature dependence over the whole temperature interval explored. A kinetic model is used to fit the calorimetric data over the complete heating rate range. Calorimetry is complemented by structural analysis through transmission electron microscopy and both standard and in-situ synchrotron X-ray diffraction. (C) 2014 AIP Publishing LLC.

[http://dx.doi.org/10.1063/1.4890106]
\end{abstract}

Solid-state reactions between two thin film materials are central to many applications in relevant areas such as electronics, materials science, and surface science. An example with important implications in nowadays microelectronic industry is the reaction between an ultrathin metal layer and silicon to form low-resistive materials to be used as metal gates. $\mathrm{NiSi},{ }^{1-3}$ or more recently $\mathrm{Ni}(\mathrm{Pt}) \mathrm{Si}^{4},{ }^{4}$ are the silicides of choice for actual sub-nm devices. The kinetics and thermodynamics of formation of those silicides are often complex due to the creation of intermediate metastable phases before the stable one sets in. For instance, NiSi formation starting from $13 \mathrm{~nm} \mathrm{Ni}$ on single-crystalline $\mathrm{Si}$ is preceded by a mixture of $\mathrm{Ni}_{2} \mathrm{Si}$ and $\mathrm{Ni}_{3} \mathrm{Si}_{2}$ phases. ${ }^{5}$ In the present study, we focus our analysis on the reaction between $\mathrm{Pd}$ and $\mathrm{Si}$, since only one stable phase forms below $800^{\circ} \mathrm{C} .^{6-8}$ Overall mechanisms of silicide formation: diffusion plus reaction, and their activation energies are relatively well described in isothermal annealings or moderate temperature up scans for a variety of silicides. However, the dependence on ramp rate is not at the same level of maturity and further investigations are required. The continuous decrease of the dimensions of electronic devices imposes stringent processing conditions to minimize interdiffusion and cross-talk effects between the different regions of the device. Fast heating processes are thus being considered to reduce the adverse impact of more traditional long-thermal treatments. ${ }^{9,10}$ In most studies involving thermodynamic or structural parameters, the heating rate achievable is limited by the experimental technique,

${ }^{a)}$ E-mail: javier.rodriguez@uab.cat. Telephone: +34935811769. i.e., by the temporal resolution to obtain accurate data. Traditional heating rates in calorimetric studies are below $10 \mathrm{~K} / \mathrm{s}$. Only very recently nanocalorimetry has been used to analyze silicide reactions at ultrafast heating rates. ${ }^{11-13}$ Needless is to say that it is experimentally challenging to measure intermediate reactions between ultrathin layers of various elements in a very wide heating rate range. In this paper, we circumvent this difficulty by using a combination of calorimetric techniques, from standard differential scanning calorimetry (DSC) to fast-scanning nanocalorimetry, to evaluate the kinetic and thermodynamic parameters that control the formation of $\mathrm{Pd}_{2} \mathrm{Si}$ from the reaction between ultrathin layers of palladium (Pd) and amorphous silicon (a-Si) by changing the heating rate by six orders of magnitude. We complement our data by in-situ synchrotron radiation analysis of phase formation and structural analysis by transmission electron microscopy.

Thin films of a-Si (15 nm thick) and Pd (12 nm thick) were sequentially grown on aluminum $(\mathrm{Al})$ foil or onto the $\mathrm{SiN}_{\mathrm{X}}$ membrane of a calorimetric chip by electron beam evaporation from targets of pure Si $99.999 \%$ and $\mathrm{Pd} 99.95 \%$. The $\mathrm{Al}$ foil was previously covered by a thin $\mathrm{SiO}_{2}$ layer to prevent interaction with the a-Si layer during heat treatments in the DSC. The foil is then folded and introduced in the DSC pan, allowing a net mass of Pd/a-Si of $\sim 0.1 \mathrm{mg}$. Given the initial thickness of the $\mathrm{Pd}$ and a-Si layers, the expected product of the reaction should be $\sim 20 \mathrm{~nm}$ of $\mathrm{Pd}_{2} \mathrm{Si}$, with a slight excess of $\mathrm{Si}$ after the reaction is completed. Since a single instrument can hardly analyze the transformation of ultrathin films in the very large heating rate interval proposed here 
(from 0.1 to $10^{5} \mathrm{~K} / \mathrm{s}$ ), we use two different setups and three methodologies to obtain accurate power vs. temperature data during the silicide formation. At slow heating rates, 0.1 and $1 \mathrm{~K} / \mathrm{s}$, the calorimetric scans were recorded with a differential scanning calorimeter (Perkin Elmer DSC 7), while for $10-10^{5} \mathrm{~K} / \mathrm{s}$ the measurements were done using membranebased nanocalorimeters. In particular, at rates above $2 \times 10^{4}$ $\mathrm{K} / \mathrm{s}$, we use quasi-adiabatic nanocalorimetry (QAnC) ${ }^{14,15} \mathrm{In}$ this last technique, a constant current pulse heats the sample at ultrafast rates and the measurement of the voltage variation of the calorimetric transducer permits to infer the heat capacity. Since the heat involved in the reaction between ultrathin layers is very small, we work in differential mode, i.e., two chips (sample and reference) are used in the measurements. To obtain the heat capacity, we subtract the contribution of the addenda, previously evaluated by multiple scans on empty nanocalorimeters. We also correct for small heat losses by carrying out measurements at various heating rates. The noise in the heat capacity at $300 \mathrm{~K}$ is $\sim 50 \mathrm{pJ} / \mathrm{K}$. In the intermediate heating rate regime, $10-10^{4} \mathrm{~K} / \mathrm{s}$, the quasi-linear increase in temperature is achieved using saw-tooth nanocalorimetry $(\mathrm{STnC})$ current-time profiles. ${ }^{16}$ In this range, heat losses are important, and we only access an apparent heat capacity. A second up scan was always performed for baseline correction. The temperature calibration of the nanocalorimeters was verified on every device after silicide formation by measuring the melting point of $\mathrm{Sn}$ and $\mathrm{Al}$ layers. Those films were grown on top of the $\mathrm{Pd}_{2} \mathrm{Si}$ layer after capping it by a $30 \mathrm{~nm}$ thick $\mathrm{SiO}_{2}$ insulating film. Cross sectional transmission electron microscopy (XTEM, Jeol JEM2011 at $200 \mathrm{kV}$ ) and XRD (Philips X'Pert, $\mathrm{Cu} \mathrm{K} \alpha$ source at $\lambda=1.5418 \AA$ ) were used to characterize the product of the transformation after various thermal treatments. For standard $\mathrm{X}$-ray characterization multilayers consisting of 10 periods of $12 \mathrm{~nm} \mathrm{Pd}+15 \mathrm{~nm} \mathrm{Si}+30 \mathrm{~nm} \mathrm{SiO}_{2}$ were grown. In-situ XRD measurements were carried out at the MSPD beamline ${ }^{17,18}$ of the ALBA Synchrotron Light Facility at Barcelona directly onto calorimetric chips.

In Figure 1, we show the calorimetric measurements covering the heating rate interval from 0.1 to $10^{5} \mathrm{~K} / \mathrm{s}$. The curves are normalized to their maximum intensity for the sake of clarity [Figures 1(a) and 1(b)]. The calorimetric traces show two broad exothermic features which shift towards higher temperatures as the heating rate increases. Only in the curve obtained at $10 \mathrm{~K} / \mathrm{s}$, using STnC [Figure 1(b)], the first exothermic jump is not resolved. This is the result of the lower sensitivity at these low heating rates. An extensive structural and calorimetric study reveals that the two broad exothermic jumps, observed in Figure 1, are composed of four calorimetric peaks associated to different mechanisms of transformation, producing most likely a single phase, $\mathrm{Pd}_{2} \mathrm{Si}$ [see supplementary material for further information on the nature and microstructure of the phases]. ${ }^{19}$ The nature of the low temperature broad change on heat capacity is inferred by analyzing the influence of several mild heat treatments to the calorimetric signal. These measurements confirm that the first exothermic jump corresponds to intermixing of $\mathrm{Pd}$ and a-Si to build up an amorphous/nanocrystalline layer at the interface followed by nucleation of $\mathrm{Pd}_{2} \mathrm{Si}$ along the $\mathrm{Pd} / \mathrm{a}-\mathrm{Si}$ interface. This is in

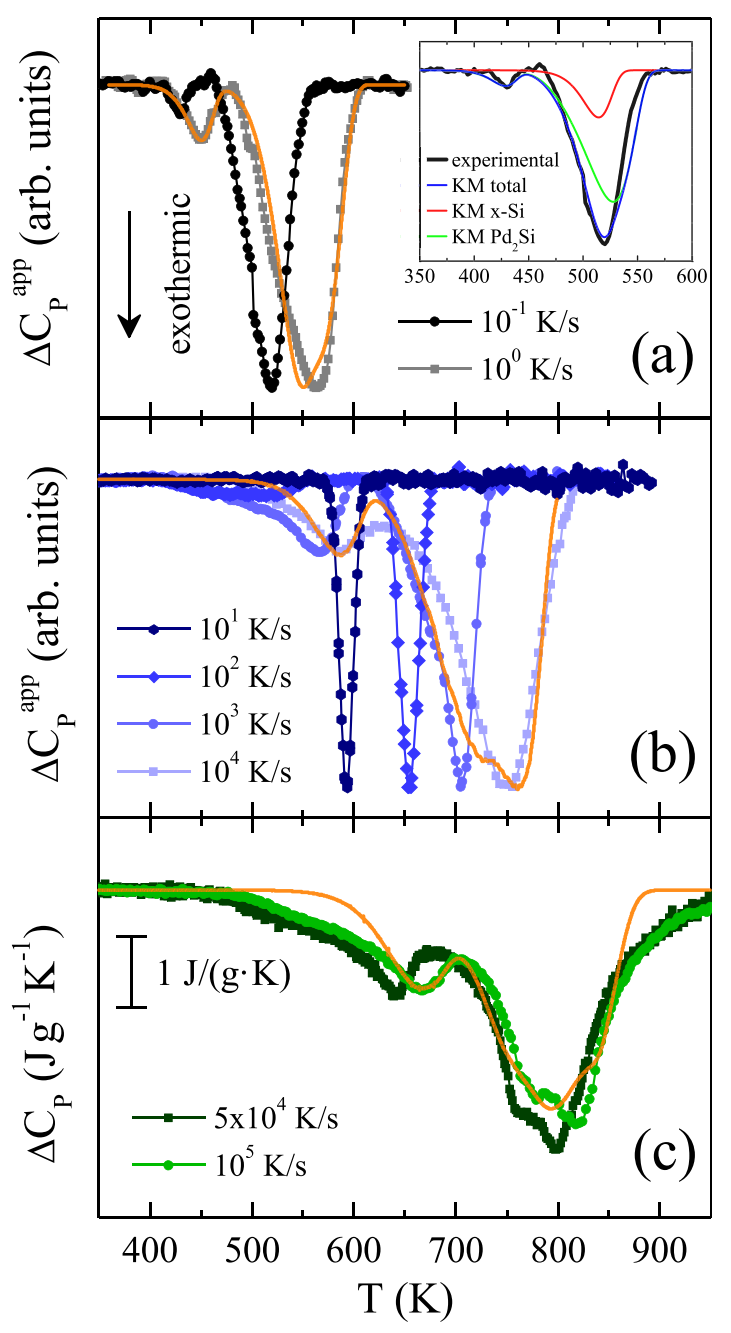

FIG. 1. Calorimetric data of the silicide reaction. Apparent heat capacity vs. temperature measured with: (a) DSC at 0.1 and $1 \mathrm{~K} / \mathrm{s}$ and (b) STnC methodology at intermediate heating rates from 10 to $10^{4} \mathrm{~K} / \mathrm{s}$. (c) Specific heat as a function of temperature obtained at $5 \times 10^{4}$ and $10^{5} \mathrm{~K} / \mathrm{s}$. The solid orange lines correspond to the calculated data using the KJMAE formalism. The inset in (a) shows the experimental data for the sample measured at $0.1 \mathrm{~K} / \mathrm{s}$ and the fitting curves obtained from the $\mathrm{KM}$ showing the $\mathrm{Pd}_{2} \mathrm{Si}$ formation (green line) and the a-Si crystallization (red line).

agreement to a significant number of previous reports that attribute the presence of the first feature to nucleation barriers that control the initial phase formation. ${ }^{20}$ The second broad exothermic jump corresponds to both the a-Si crystallization (x-Si) and the vertical growth of the $\mathrm{Pd}_{2} \mathrm{Si}$ phase [see supplementary material and Figure 1(a), inset]. In fact, the large enthalpy associated with the DSC and QAnC calorimetric traces [Figures 1(a) and 1(c)] with respect to pure $\mathrm{Pd}_{2} \mathrm{Si}$ formation clearly indicates other processes are active in this temperature range. The enthalpy of the complete reaction at the fastest rates is $93 \mu \mathrm{J}$, which includes $18 \mu \mathrm{J}$ due to intermixing at the interface, $12 \mu \mathrm{J}$ as a result of the crystallization of $11 \mathrm{~nm}(\sim 26 \mathrm{ng})$ of a-Si, ${ }^{13}$ and $63 \mu \mathrm{J}$ due to the formation of $180 \mathrm{ng}$ of $\mathrm{Pd}_{2} \mathrm{Si}^{21}$

To gain more insight into the mechanisms that control the phase transformation in the whole temperature interval, we use the Kolmogorov-Johnson-Mehl-Avrami-Erofeev (KJMAE) formalism to fit the calorimetric traces. ${ }^{22,23}$ For the sake of clarity, we only include fitting curves for the highest heating rate of every measurement technique (solid 
orange lines in Figure 1). The complete set of fittings and the equations used to describe the main processes are described in detail in supplementary material. ${ }^{19}$ The kinetic model (KM) incorporates the following processes: (i) nucleation of $\mathrm{Pd}_{2} \mathrm{Si}$ within the $\mathrm{Pd}_{\mathrm{x}} \mathrm{Si}_{1-\mathrm{x}}$ interfacial region, (ii) a-Si crystallization through a growth front from the interface, and (iii) vertical growth of $\mathrm{Pd}_{2} \mathrm{Si}$. Note that the kinetic model does not include the intermixing reaction. The crystallization of a-Si is catalyzed by the presence of the $\mathrm{Pd}_{2} \mathrm{Si}$ phase and therefore occurs at lower temperatures than expected for pure $\mathrm{Si}$, in agreement with many previous reports. ${ }^{24,25}$ According to the kinetic model, the crystallization of a-Si and the vertical growth of $\mathrm{Pd}_{2} \mathrm{Si}$ are fully overlapped [inset of Figure 1(a) and supplementary material].

The analysis and interpretation of the temperature evolution of those exothermic events is the main outcome of the present work. The general trend can be rapidly appreciated from Figure 1. As the heating rate is increased up to $10^{5} \mathrm{~K} / \mathrm{s}$, the onset and maximum of the peaks shift to higher temperatures as expected for thermally activated processes. To obtain a first insight, we use a simplified methodology, the Kissinger plot (Figure 2), to estimate the average activation energy of the transformation during the heating ramp. ${ }^{26} \mathrm{We}$ consider only two main processes and average values of the heating rate, since in STnC and QAnC methodologies the heating rate is not constant throughout the measurement when silicide formation occurs.

As illustrated in Figure 2, both peaks exhibit a linear behavior in the whole temperature interval with activation energies of $1.38 \pm 0.04 \mathrm{eV} /$ at for the first peak and $1.75 \pm 0.04 \mathrm{eV} /$ at for the second one. This average energy values are slightly higher than those previously reported by Homma et al. $^{27}$ in couples of $\mathrm{Pd} / \mathrm{a}-\mathrm{Si}: \mathrm{H}$, where an activation energy of $1.1 \mathrm{eV} /$ at for a reaction-limited $\mathrm{Pd}_{2} \mathrm{Si}$ formation and $1.4 \mathrm{eV} /$ at for a diffusion-limited growth was found. Although it is normally assumed that $\mathrm{Pd}$ and $\mathrm{Si}$ fluxes are coupled and both contribute to $\mathrm{Pd}_{2} \mathrm{Si}$ growth, the activation energy evaluated here for the second peak coincides with the value of $1.7 \mathrm{eV} /$ at found for Si mobility through polycrystalline $\mathrm{Pd}_{2} \mathrm{Si}^{28}$

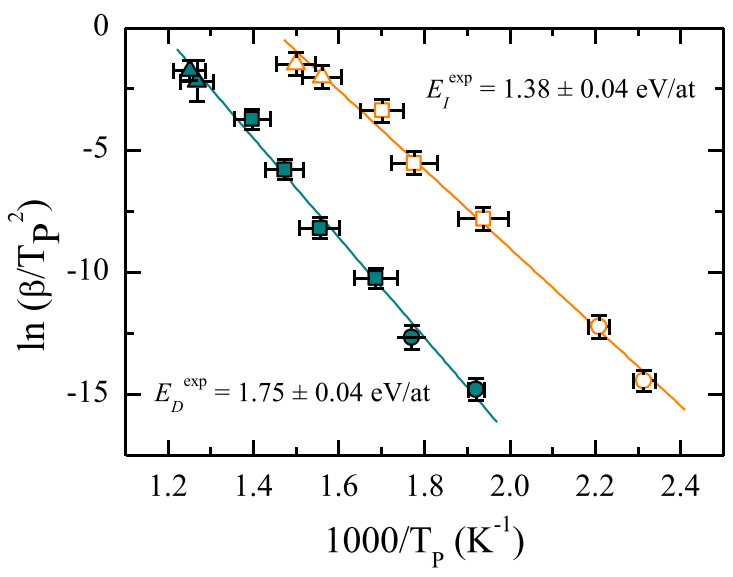

FIG. 2. Kissinger plot for the first (open symbols) and second (filled symbols) exothermic peaks. Data obtained from QAnC at fast heating rates (triangles), from conventional DSC at slower rates (circles), and from STnC at intermediate heating rates (squares). Continuous lines represent best fits to the data which yield the activation energies.
Table I highlights the excellent agreement between the activation energies obtained for the nucleation and vertical growth of $\mathrm{Pd}_{2} \mathrm{Si}$ using the kinetic modeling and those obtained using the Kissinger methodology. The difference between the simulated data and the experimental calorimetric traces in the low temperature region of Figure 1 highlights the increased importance of the initial interdiffusion as the heating rate increases. Interestingly, the ratio between the areas associated to the two transformation mechanisms (nucleation at the interface and vertical growth) involving $\mathrm{Pd}_{2} \mathrm{Si}$ is not constant and shows a clear dependence with the heating rate. The variation can be easily inferred from Figure 1. The fastest is the heating rate, the higher is the proportion of $\mathrm{Pd}_{2} \mathrm{Si}$ formed during the nucleation stage compared to the amount transformed during the vertical growth. This is reflected in the model by the parameter $L_{0}$, which indicates the initial height occupied by the $\mathrm{Pd}_{2} \mathrm{Si}$ nuclei [Eq. (7) in supplementary material]. We identify the nucleation region with the premixed zone at the interface that has reached the required stoichiometry to initiate nuclei formation. Figure 3(a) shows the evolution of the thickness of this nucleation zone as a function of the heating rate. While at the slowest rates of $0.1-1 \mathrm{~K} / \mathrm{s}$, the nucleation process at the interface creates a $1.2 \mathrm{~nm}$ thick $\mathrm{Pd}_{2} \mathrm{Si}$ layer, at fastest heating rate of $10^{5} \mathrm{~K} / \mathrm{s}$ the thickness of the interfacial layer grows up to $4.8 \mathrm{~nm}$, four times larger.

The interfacial formation mechanism of $\mathrm{Pd}_{2} \mathrm{Si}$ at the lowest and highest heating rates is schematized in Figure 3(b). We interpret these differences as follows: at low heating rates $(0.1-1 \mathrm{~K} / \mathrm{s})$, a thin mixed disordered region forms between $\mathrm{Pd}$ and a-Si at temperatures below $400 \mathrm{~K}$. This region acts as the seed layer for the formation of the initial nuclei of $\mathrm{Pd}_{2} \mathrm{Si}$ that occurs around $450 \mathrm{~K}$ (1st calorimetric peak). On increasing the temperature, the $\mathrm{Pd}_{2} \mathrm{Si}$ grows vertically by $\mathrm{Pd}$ and/or $\mathrm{Si}$ diffusion through the $\mathrm{Pd}_{2} \mathrm{Si}$ interlayer. However, at ultrafast heating rates above thousands of $\mathrm{K} / \mathrm{s}$, the scheme changes dramatically. The activation energy for nucleation drives the nucleation peak towards higher temperatures $(\sim 650 \mathrm{~K})$, enabling substantial intermixing before the interfacial layer has formed. As a consequence, the mixed disordered region is now four times thicker than the one obtained at slower heating rates. Since we assume nucleation only occurs within the premixed region, the heat dissipated during nucleation of $\mathrm{Pd}_{2} \mathrm{Si}$ is also $4 \times$ larger. Remarkably, in spite of the thickness increase of the nucleation-driven interfacial $\mathrm{Pd}_{2} \mathrm{Si}$ layer, the vertical growth strictly follows an Arrhenius temperature dependence which may indicate that the diffusion-controlled process occurs via

TABLE I. Activation energies for the $\mathrm{Pd}_{2} \mathrm{Si}$ nucleation $\left(E_{I}\right), \mathrm{Pd}_{2} \mathrm{Si}$ vertical growth $\left(E_{D}\right)$, and a-Si crystallization $\left(E_{U}\right)$ obtained from the kinetic model (KJMAE formalism) and experimentally (Kissinger method). $L_{T}$ corresponds to the final thickness of the $\mathrm{Pd}_{2} \mathrm{Si}$ film.

\begin{tabular}{llc}
\hline \hline & KJMAE formalism & Kissinger method \\
\hline$E_{I}$ & $(1.38 \pm 0.05) \mathrm{eV} / \mathrm{at}$ & $(1.38 \pm 0.04) \mathrm{eV} / \mathrm{at}$ \\
$E_{D}$ & $(1.81 \pm 0.05) \mathrm{eV} / \mathrm{at}$ & $(1.75 \pm 0.04) \mathrm{eV} / \mathrm{at}$ \\
$E_{U}$ & $(1.72 \pm 0.05) \mathrm{eV} / \mathrm{at}$ & \\
$L_{T}$ & $(20.3 \pm 2.0) \mathrm{nm}$ \\
\hline \hline
\end{tabular}




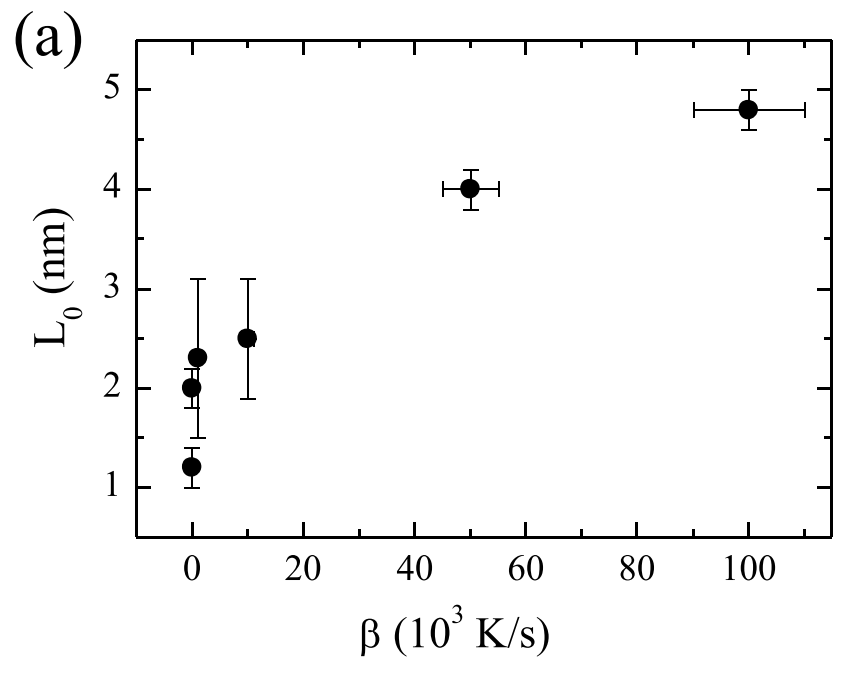

(b)

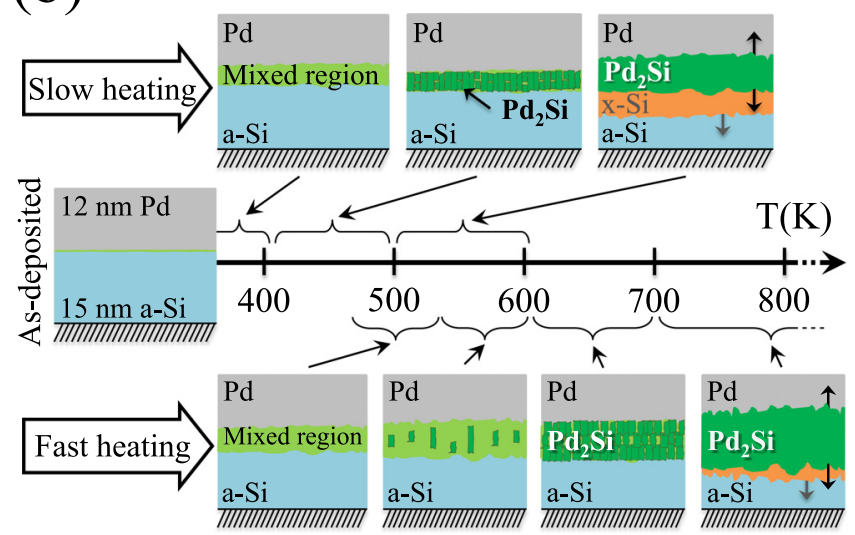

FIG. 3. (a) Thickness of the initial $\mathrm{Pd}_{2} \mathrm{Si}$ that forms at the a-Si/Pd interface as a function of the heating rate. (b) Schematics of the initial growth mode at the interface a-Si/Pd for slow (top) and fast (bottom) heating.

fast diffusion paths, probably through grain boundaries connecting the Pd and Si reservoirs.

We have shown that the reaction of ultrathin films of Pd and $\mathrm{a}-\mathrm{Si}$ is dominated by four processes: intermixing forming disordered $\mathrm{Pd}_{\mathrm{X}} \mathrm{Si}_{1-\mathrm{X}}$ region at the a-Si/Pd interface, nucleation of $\mathrm{Pd}_{2} \mathrm{Si}$ in the premixed region, crystallization of $\mathrm{a}-\mathrm{Si}$, and simultaneously vertical growth of the $\mathrm{Pd}_{2} \mathrm{Si}$ phase. More fundamentally, when analyzed over a wide heating rate interval of six orders of magnitude, from 0.1 to $10^{5} \mathrm{~K} / \mathrm{s}$, the formation of $\mathrm{Pd}_{2} \mathrm{Si}$, both with respect to the nucleation and the vertical growth, exhibits a pure Arrhenius behavior. The enhanced mass diffusion observed during the initial stages of the reaction increases with heating rate, due to the thermally activated nucleation of the $\mathrm{Pd}_{2} \mathrm{Si}$ phase.

Researchers from GNaM acknowledge financial support from Generalitat de Catalunya and Ministerio de Economía y Competitividad through Grant Nos. SGR2009-01225 and
MAT2010-15202, respectively, and from Marie Curie European Reintegration Grant within the 7th European Community Framework Programme. The authors acknowledge the Servei de Microscòpia from the Universitat Autònoma de Barcelona for sample preparation and microscopy images. Synchrotron measurements were performed at MSPD beamline at ALBA Synchrotron Light Facility with the collaboration of ALBA staff.

${ }^{1}$ P. Gas, F. M. d'Heurle, F. K. LeGoues, and S. J. La Placa, J. Appl. Phys. 59, 3458 (1986).

${ }^{2}$ S. Gaudet, P. Desjardins, and C. Lavoie, J. Appl. Phys. 110, 113524 (2011).

${ }^{3}$ D. Mangelinck, K. Hoummada, and I. Blum, Appl. Phys. Lett. 95, 181902 (2009).

${ }^{4}$ D. Kim, A. Domenicucci, and S. S. Iyer, J. Appl. Phys. 103, 073708 (2008).

${ }^{5}$ C. Rivero, P. Gergaud, M. Gailhanou, O. Thomas, B. Froment, H. Jaouen, and V. Carron, Appl. Phys. Lett. 87, 041904 (2005).

${ }^{6}$ K. Hoummada, A. Portavoce, C. Perrin-Pellegrino, D. Mangelinck, and C. Bergman, Appl. Phys. Lett. 92, 133109 (2008).

${ }^{7}$ M. Wittmer and K. N. Tu, Phys. Rev. B 27, 1173 (1983).

${ }^{8}$ R. Suryana, O. Nakatsuka, and S. Zaima, Jpn. J. Appl. Phys., Part 1 50, 05EA09 (2011).

${ }^{9}$ H.-Y. Chen, C.-Y. Lin, M.-C. Chen, C.-C. Huang, and C.-H. Chien, J. Electrochem. Soc. 158, H840 (2011).

${ }^{10}$ H.-Y. Chen, C.-Y. Lin, C.-C. Huang, and C.-H. Chien, Microelectron. Eng. 87, 2540 (2010).

${ }^{11}$ L. P. Cook, R. E. Cavicchi, N. Bassim, S. Eustis, W. Wong-Ng, I. Levin, U. R. Kattner, C. E. Campbell, C. B. Montgomery, W. F. Egelhoff, and M. D. Vaudin, J. Appl. Phys. 106, 104909 (2009).

${ }^{12}$ R. K. Kummamuru, L. De La Rama, L. Hu, M. D. Vaudin, M. Y. Efremov, M. L. Green, D. A. LaVan, and L. H. Allen, Appl. Phys. Lett. 95, 181911 (2009).

${ }^{13}$ M. Molina-Ruiz, A. F. Lopeandía, M. González-Silveira, Y. Anahory, M. Guihard, G. Garcia, M. T. Clavaguera-Mora, F. Schiettekatte, and J. Rodríguez-Viejo, Appl. Phys. Lett. 102, 143111 (2013).

${ }^{14}$ M. Y. Efremov, E. A. Olson, M. Zhang, F. Schiettekatte, Z. Zhang, and L. H. Allen, Rev. Sci. Instrum. 75, 179 (2004).

${ }^{15}$ A. F. Lopeandía, J. Rodríguez-Viejo, M. Chacón, M. T. Clavaguera-Mora, and F. J. Muñoz, J. Micromech. Microeng. 16, 965 (2006).

${ }^{16}$ A. F. Lopeandia, J. Valenzuela, and J. Rodríguez-Viejo, Sens. Actuators, A 143, 256 (2008).

${ }^{17}$ F. Fauth, I. Peral, C. Popescu, and M. Knapp, Powder Diffr. 28, S360 (2013).

${ }^{18}$ M. Knapp, I. Peral, L. Nikitina, M. Quispe, and S. Ferrer, Z. Kristallogr. Proc. 1, 137 (2011).

${ }^{19}$ See supplementary material at http://dx.doi.org/10.1063/1.4890106 for more details on calorimetric traces and kinetic model.

${ }^{20}$ E. Ma, C. V. Thompson, and L. A. Clevenger, J. Appl. Phys. 69, 2211 (1991).

${ }^{21}$ J. C. C. Fan and C. H. Anderson, Jr., J. Appl. Phys. 52, 4003 (1981).

${ }^{22}$ K. R. Coffey, L. A. Clevenger, K. Barmak, D. A. Rudman, and C. V. Thompson, Appl. Phys. Lett. 55, 852 (1989).

${ }^{23}$ M. Gonzalez-Silveira, J. Rodriguez-Viejo, G. Garcia, F. Pi, F. J. Ager, J. L. Lábár, A. Barna, M. Menyhárd, and L. Kótis, J. Appl. Phys. 100, 113522 (2006).

${ }^{24}$ D. He, J. Y. Wang, and E. J. Mittemeijer, J. Appl. Phys. 97, 093524 (2005).

${ }^{25}$ Z. Wang, J. Wang, L. Jeurgens, and E. Mittemeijer, Phys. Rev. Lett. 100, 125503 (2008).

${ }^{26}$ H. E. Kissinger, Anal. Chem. 29, 1702 (1957).

${ }^{27}$ K. Homma, T. Koike, S. Ando, K. Adachi, and M. Motohashi, Electron. Commun. Jpn., Part 2 80, 12 (1997).

${ }^{28}$ E. C. Zingu, J. W. Mayer, C. Comrie, and R. Pretorius, Phys. Rev. B 30, 5916 (1984). 